\title{
A FUNÇÃO DOS INTELECTUAIS E O PAPEL DA ESCOLA NA ORGANIZAÇÃO DA CULTURA
}

\author{
Aparecida Carneiro Pires ${ }^{1}$ \\ Diego Assis de Brito ${ }^{2}$ \\ Maria Cecília de Paula Silva ${ }^{3}$ \\ UFBA \\ Tairone Rodrigues Paiva ${ }^{4}$ \\ UNEB
}

\section{RESUMO}

Este texto busca refletir sobre temática da educação atual, a partir dos escritos de Antônio Gramsci, em especial acerca da função dos intelectuais "orgânicos" dentro de uma visão crítica da sociedade visando à transformação social. Centralmente, estaremos dialogando com a compreensão de intelectuais apresentada por Gramsci em seus escritos do cárcere e a função dos mesmos. Reconhecemos a importância desta concepção para a formação de um pensamento crítico e, de certa forma, determinante nos processos culturais, educacionais, societários que contribuam para a revolução. Trata-se de um estudo bibliográfico, de abordagem qualitativa. Apontamos a importância de uma cultura baseada na educação humanista, proposta pela escola unitária de Gramsci, a compreensão histórica do conhecimento popular na ação pedagógica de resistência e as bases para a construção de outra hegemonia, a do proletariado.

Palavras-chave: educação; emancipação; intelectuais; hegemonia e cultura.

\section{THE FUNCTION OF INTELLECTUALS AND THE ROLE OF SCHOOL IN THE ORGANIZATION OF CULTURE}

\begin{abstract}
This text reflects the theme of the education current, from the writings of Antonio Gramsci, specially about the function of intellectuals "organic" within a critical view of society for social transformation. The focus is the dialogue with the understanding of intellectuals by Gramsci in his writings of the prision and its social function. We recognize the importance of this concept for the formation of a critical thinking and, in some ways, determinant in the cultural, educational, corporate processes that contribute to the revolution. This is a bibliographical study of qualitative approach. We point out the importance of a culture based on humanistic education, proposed by the Unitarian School of Gramsci, the historical understanding of popular knowledge in pedagogical action of resistance and the bases for the construction of another hegemony of proletariat.
\end{abstract}

Keywords: education; emancipation; intellectuals; culture and hegemony.

\section{Introdução}

A complexificação da sociabilidade capitalista tem nos deixado inúmeras perguntas, dentre elas, algumas que consideramos de fundamental relevância acerca do papel dos intelectuais "orgânicos" 5 na atualidade: será que estes têm resistido às problemáticas impostas pela política neoliberal ou têm exercido o papel de coadjuvantes e/ou elaboradores das mesmas? Nas atividades deste intelectual orgânico, a cultura tem sido um constructo importante na valorização e respeito à cultura da classe 
trabalhadora? Como tem se dado a compreensão histórica do conhecimento popular, da ação pedagógica de resistência e da ação orgânica dos intelectuais na construção de uma contra-hegemonia, para outra hegemonia diferente da posta, perspectivando uma vida plena de sentido para todos, que aponte outra globalização, com condições de equidade econômica e social?

$\mathrm{Na}$ tentativa de refletir sobre tais indagações é que objetivamos pensar sobre a função dos intelectuais diante do desafio atual, qual seja: propor um modelo de sociedade diferente do posto, que no caso de Gramsci, tem inclinações socialistas. Utilizando-nos das produções de teóricos que, embasados em questões apontadas por Gramsci, têm se dedicado a compreender a ação dos intelectuais em nosso país frente às exigências da atualidade.

Concordando com José Mario Angeli (2011) consideramos que Antônio Gramsci é sempre inspirador e provocativo, uma vez que ele nos propicia a reflexão, a análise da sociedade em que vivemos e, fundamentalmente, nos faz pensar em alternativas e possibilidades de mudanças, desafio este que cabe a toda a humanidade. Vivemos na constante dialética do centro e das periferias. Numa análise do desenvolvimento desigual e combinado na dialética do centro e da periferia, destaca-se no Brasil a reflexão sobre os rumos da política no sentido do trabalho dos intelectuais orgânicos na educação que apontem para uma práxis transformadora. Práxis aqui considerada no sentido atribuído por Marx (Cf. Tom Bottomore,1997), como atividade criadora, criativa e autocriativa, em que os seres humanos transformam a si mesmos e o mundo humano e histórico.

A atualidade sociocultural, política e educacional nos impregnam de uma aparente impossibilidade de mudanças e um "conformismo" forçado e forjado no cotidiano social ampliado pela situação política atual de retirada dos intelectuais "orgânicos", cooptados pelo projeto político neoliberal, o que exige uma nova postura dos intelectuais "orgânicos" brasileiros, no sentido de aguçar o pensamento crítico de forma a dar maior visibilidade e organização às possibilidades de transformação social. Diante desta problemática e das constantes crises do modo de produção capitalista, as quais são geradas pelo próprio sistema com sua manutenção de queima da superprodução, torna-se fundamental estabelecer o diálogo a respeito do que seria o intelectual, a partir de Gramsci, na compreensão da realidade atual capitalista e seus métodos de produção e controle dos resultados, da dialética entre centro e periferia, além de apontar proposições superadoras e embasadas na própria realidade, não somente na forma como se apresenta, mas principalmente em sua essência.

Este artigo se propõe a discutir a importância e a função desses intelectuais dentro de uma visão crítica da sociedade para a transformação e superação dos problemas da realidade atual e histórica. Apoiaremo-nos, principalmente, nos estudos de Gramsci sobre intelectuais e sua função social, reconhecendo a sua atualidade e necessária contextualização para a formação de um pensamento crítico, e, de certa forma, determinante nos processos culturais, educacionais e societários.

\section{Os intelectuais em Gramsci}

Inicialmente, o que seria o intelectual para Gramsci? $\mathrm{O}$ que definiria o intelectual? Se considerarmos o senso comum, um intelectual é comumente definido como um ser intelectual, uma pessoa que possui ou deveria possuir poderes superiores do intelecto. Já para Gramsci o intelectual seria definido de forma significamente diferente desta compreensão. Para ele, o intelectual não é aquele que possui poderes superiores do intelecto, mas aquele que, na sociedade, tem como função social a responsabilidade de produzir conhecimento, e/ou inspirar, sugerir, introduzir 
conhecimento. Gramsci, no seu segundo Caderno do Cárcere (2010), aponta que dentre as várias formas que assumiu o processo histórico real de formação das diversas categorias intelectuais, as mais importantes dessas formas são duas:

1) Todo grupo social, nascendo no terreno originário de uma função essencial no mundo da produção econômica cria para si, ao mesmo tempo, organicamente, uma ou mais camadas de intelectuais que lhe dão homogeneidade e consciência da própria função, não apenas no campo econômico, mas também no social e político: o empresário capitalista cria consigo o técnico da indústria, o cientista da economia política, o organizador de uma nova cultura, de um novo direito, etc., etc.[...]Pode-se observar que os intelectuais "orgânicos" que cada nova classe cria consigo e elabora em seu desenvolvimento progressivo são, na maioria dos casos, "especializações" de aspectos parciais da atividade primitiva do tipo social novo que a nova classe deu à luz.(...)

2) Todo grupo "essencial", contudo, emergindo na história a partir da estrutura econômica anterior e como expressão do desenvolvimento desta estrutura, encontrou - pelo menos na história que se desenrolou até nossos dias - categorias intelectuais preexistentes, as quais apareciam, aliás, como representantes de uma continuidade histórica que não foi interrompida nem mesmo pelas mais complicadas e radicais modificações das formas sociais e políticas. A mais típica destas categorias intelectuais é a dos eclesiásticos, que monopolizaram durante muito tempo alguns serviços importantes: a ideologia religiosa, isto é, a filosofia e a ciência da época, com a escola, a instrução, a moral, a justiça, a beneficência, a assistência, etc. (GRAMSCI 2010, p. 15-16)

Dando continuidade à compreensão da categoria dos intelectuais, Semeraro (2006) elucida a diferença entre designição de intelectuais "orgânicos" e intelectuais "tradicionais". Os segundos, referem-se aos intelectuais presos ainda a uma formação socioeconômica superada: "Eram os intelectuais estagnados no mundo agrário do Sul na Itália. Eram o "clero", "os funcionários", a "casa militar", "os acadêmicos" voltados a manter os camponeses atrelados a um status quo que não fazia mais sentido. (SEMERARO 2006, p. 134)

O referido autor ainda afirma que, para Gramsci, os intelectuais "orgânicos" são aqueles que fazem parte de um organismo vivo em expansão, estando interligados com o mundo do trabalho, com as organizações políticas e culturais mais avançadas que o seu grupo social desenvolve para dirigir a sociedade. Desse modo, são orgânicos os intelectuais que,

Além de especialistas na sua profissão que os vincula profundamente ao modo de produção do seu tempo, elaboram uma concepção éticopolítica que os habilita a exercer funções culturais, educativas e organizativas para assegurar a hegemonia social e o domínio estatal da classe que representam. Conscientes de seus vínculos de classe, manifestam sua atividade intelectual de diversas formas: no trabalho como técnicos e especialistas dos conhecimentos mais avançados, no interior da sociedade civil para construir o consenso em torno do projeto da classe que defendem, na sociedade política para garantir as 
funções jurídico-administrativas e a manutenção do poder do seu grupo social. (SEMERARO, 2006, p. 135)

No que concerne aos intelectuais "tradicionais", o supracitado autor, afirma que estes ficavam empalhados dentro de um mundo antiquado, permaneciam fechados em abstratos exercícios cerebrais, eruditos e enciclopédicos, até mais alheios às questões centrais da própria história. Fora do próprio tempo, os intelectuais "tradicionais" consideravam-se independentes, acima das classes e das vicissitudes do mundo, cultivavam uma aura de superioridade com seu saber livresco. A sua "neutralidade" e o seu distanciamento, na verdade, os tornavam incapazes de compreender o conjunto do sistema de produção e das lutas hegemônicas, onde fervia o jogo decisivo do poder econômico e político. Com isso, acabavam sendo excluídos não apenas dos avanços da ciência, mas também das transformações em curso na própria vida real.

Visto o exposto acima, podemos afirmar que os intelectuais têm a função principal de produzir e/ou organizar um conjunto e indicações gerais, normas, instruções, consoante às quais deve-se proceder no contexto que estão inseridos. Levando em consideração a tendência ideológica de Gramsci, estes intelectuais devem favorecer à classe operária e suas necessidades. Gramsci indica que não é o fato de pensar que sugere que as pessoas tenham a função de intelectual, na medida em que considera que todos os seres humanos são intelectuais, já que pensam; não há atividade humana se não houver a atividade intelectual, do pensar e refletir para agir: o homo faber não pode se separar do homo sapiens: "todo homem, fora de sua profissão, desenvolve uma atividade intelectual qualquer, ou seja, é um ‘filósofo`, um artista, um homem de gosto, participa de uma concepção de mundo, possui uma linha consciente de conduta moral, contribui assim para manter ou para modificar uma concepção do mundo, isto é, para suscitar novas maneiras de pensar" (GRAMSCI, 2000, p. 53).

O ponto crucial de sua definição, no entanto, é que, enquanto todos os homens são intelectuais na medida em que eles pensam, refletem, organizam as idéias para agir, nem todos os homens têm na sociedade a função de intelectuais. Para esclarecer esta questão, Gramsci exemplifica que, mesmo sabendo que todos nós, em algum momento da vida, possamos fritar um ovo ou pregar um botão que caiu do casaco, nem todos serão considerados cozinheiros ou alfaiates.

Outra questão importante a destacar é a ampliação que Gramsci promove à definição padrão do intelectual, incluindo nesta definição os educadores, na medida em que ele considera que os intelectuais possuem a responsabilidade de transmitir o conhecimento aos outros, garantindo, de alguma forma, a reprodução de uma determinada concepção de mundo.

Relevante destacar que para Gramsci, no que se refere à função dos intelectuais, a questão da organização possui uma tensão em relação a sua importancia. Esta tensão é expressa na pouca capacidade das classes subalternas para se organizarem. Ela pode ser interpretada como uma das fraquezas mais significativas, o que, de certa maneira, os impede de superar a própria subordinação. Na compreensão deste autor, em qualquer situação e para qualquer grupo social, a organização é ponto crucial para se alcançar determinada situação em que a sua concepção de mundo se torne hegemônica, e que possa reproduzir esta hegemonia.

O modo de ser do novo intelectual não pode mais consistir na eloquência, motor exterior e momentâneo dos afetos e das paixões, mas numa inserção ativa na vida prática, como construtor, organizador, 'persuasor permanentemente`, já que não apenas orador puro - mas superior ao 
espírito matemático abstrato; da técnica-trabalho, chega à técnica-ciência e à concepção humanista histórica, sem a qual permanece 'especialista' e não se torna 'dirigente' (especialista + político), (id. p.53).

Dessa forma, o trabalho organizativo passa a ser compreendido como parte integrante do processo de produção de conhecimento para que se possa agir no mundo como sujeito, e não como uma ação domesticada; essa seria para Gramsci a função do Intelectual. Refletir sobre a realidade social passa necessariamente pela reflexão a respeito da função deste intelectual na sociedade atual, na lógica da cultura e da relação entre hegemonia ${ }^{6}$ e contra-hegemonia ${ }^{7}$.

Laudicéa de Souza Pinto, afirma que intelectual para Gramsci não quer dizer uma formação acadêmica específica, mas uma ação social, um certo tipo de agente capaz de fazer a ligação entre superestrutura e infraestrutura, independente de sua escolaridade específica, mas relacionada diretamente com o "lugar" que ocupa nas relações materiais/sociais de uma determinada produção social.

O que separa um grupo do outro (intelectual e o não intelectual) não é a forma de conhecimento em si, mas um tipo de lógica de pensamento mantido pelo capitalismo, em que permanece de forma hegemônica a separação do trabalho manual do intelectual.

Portanto, será, na sua forma de se articular com a classe revolucionária (ou não), que poderá cumprir a sua "função de agentes da hegemonia", porque o "valor intrínseco" da atividade intelectual, só tem razão de ser quando cumprida esta função, lutar para a hegemonia do proletariado; contribuir efetivamente para a unidade dialética entre ação e ideia, teoria e prática, numa permanente reflexão sobre o comportamento político e articulação entre proletariado e o intelectual dentro da classe.

A relação intelectual/classe não deve ser vista como uma pura abstração, pois se trata de algo concreto e que exige que o intelectual não abra mão, independente de sua origem de classe, de ocupar este lugar, desenvolvendo uma "práxis" coerente com a luta de se fazer da classe trabalhadora, a classe hegemônica.

Esta atuação fundamenta-se em uma espécie de elevação intelectual coletiva referente à classe trabalhadora, buscando criar as condições necessárias que proporcionem, dentro das próprias contradições da sociedade atual, esta possibilidade e a atuação militante (práxis social) no processo de transformação, transição e revolução.

Segundo Gramsci (1982) todo grupo social ao mesmo tempo em que se constitui sobre a base original da função que assume no campo da produção econômica, cria organicamente uma ou mais camadas de intelectuais que lhe asseguram homogeneidade e consciência de sua própria função, não só no setor econômico, como também nos setores social e político. Essas camadas intelectuais não surgem de forma abstrata, democrática, liberal etc., mas sim de relações concretas dentro do processo histórico de produção social. Nesse sentido, Gramsci utiliza a expressão "questão meridional" para elucidar a diferenciação que existe entre algumas camadas de intelectuais a partir de relações concretas que estas têm dentro do processo histórico de produção social na Itália. Nesta perspectiva, a designação de intelectuais "orgânicos" é distinta dos intelectuais "tradicionais".

Esta visão fragmentada entre os intelectuais considerados "orgânicos" e os considerados "tradicionais" acontecia por causa da ideia de que o sul era atrasado em relação ao norte. Esta observação sobre o comportamento dos intelectuais do norte advém de uma posição preconceituosa destes em relação aos do sul. ${ }^{8}$

Para ilustrar o apresentado acima, tomamos as palavras de (MAESTRI; CANDREVA) para enfatizar que 
para o grupo ordem nova a necessária união política e social entre os trabalhadores industriais do norte e rurais do sul exigia, antes de tudo, a denuncia-superação dos preconceitos difundidos entre o operariado urbano pela ideologia burguesa, comumente através do próprio partido socialista, de que as regiões meridionais eram atrasadas, não por razões históricas ou devido à exploração capitalista, mas por serem habitadas por 'seres' 'biologicamente' inferiores, devendo-se ao sul agrário que a Itália não se desenvolvesse de forma mais rápida. (MAESTRI; CANDREVA, 2007, p.181)

Isto posto pode-se avaliar a condição dos camponeses de ultrapassar quaisquer das questões de organização de um levante, pois esbarravam, por outro lado, nos muros do pensamento imposto pelos intelectuais "tradicionais" sulistas, que, por sua vez, reproduziam as ideias dos grandes proprietários de terra'.

Para que esta questão fique mais visível nos discursos dos grandes proprietários de terras do sul, Maestri e Candreva explicitam:

para Gramsci o camponês meridional ligava-se aos grandes proprietários fundiários através do intelectual médio que, presente em todas as aldeias, adaptava e infundia as visões de mundo dos grandes proprietários no mundo camponês. Porém, essas concepções não eram definidas, preparadas, elaboradas pelo "intelectual médio", a quem Gramsci define como personagem sem alma e imaginação. Elas eram geradas pelos grandes intelectuais, representantes dos latifundiários, que conformavam um poderoso "bloco intelectual". (MAESTRI; CANDREVA, 2007, p. 182, 183)

Partindo do apresentado, faz-se necessária a compreensão das condições impostas pelos grandes proprietários de terra em relação a uma proposta qualquer de intervenção, ou qualquer alcance das massas campesinas em se tornares senhores de suas próprias ideias, portanto, de assumirem a direção de quaisquer que fossem o direcionamento que quisessem dar às condições impostas. Ou seja, não havia espaço para que o camponês se emancipasse enquanto produtor de um pensamento autônomo, pois a estrutura, a estratificação social não permitia que o camponês pudesse alcançar qualquer posto para além da sua condição de trabalhador do campo.

\section{O intelectual e a escola: uma das "armas" para a superação da sociedade capitalista}

Gramsci nos deixou um grande legado, principalmente no que diz respeito ao pensamento e ao conceito de hegemonia e cultura, ambas sendo pensadas na perspectiva da elaboração e da construção da cultura das classes subalternas.

Consideramos necessária a interligação do mundo do trabalho com o universo da ciência, com as humanidades, e a visão política de conjunto, bases para a formação do que Gramsci defende em seu novo princípio educativo, sendo, portanto, o pilar formativo do intelectual orgânico: a sua profunda vinculação à cultura e à história.

Em sua obra "A Organização da Escola e da Cultura", Gramsci (1988) inicia mencionando que, em geral, na civilização moderna, todas as atividades práticas se tornaram tão complexas, e as ciências se mesclaram de tal modo à vida, que toda atividade prática tende a criar uma escola para os próprios dirigentes e especialistas e, 
consequentemente, tende a criar um grupo de intelectuais especialistas de nível mais elevado, que ensinam nestas escolas. Assim, ao lado do tipo de escola que poderíamos chamar de "humanista", destinado a desenvolver em cada indivíduo humano a cultura geral ainda indiferenciada, o poder fundamental de pensar e de saber se orientar na vida, foi-se criando, paulatinamente, todo um sistema de escolas particulares de diferente nível, para inteiros ramos profissionais, ou para profissionais, ou para profissões já especializadas e indicadas mediante uma precisa individualização. Pode-se dizer, aliás, que a crise escolar que hoje se agudiza liga-se precisamente ao fato de que este processo de diferenciação e particularização ocorre de um modo caótico, sem princípios claros e precisos, sem um plano bem estudado e conscientemente fixado: a crise do programa e da organização escolar, isto é, da orientação geral de uma política de formação dos modernos quadros intelectuais, é em grande parte um aspecto e uma complexificação da crise orgânica mais ampla e geral. (GRAMSCI p. 117, 118)

O que não se pode perder de vista é que, se a escola "pública" atende aos interesses do capital, o que se pode esperar da escola particular? Por isso Gramsci defende a escola unitária de formação humanista:

[...] A escola unitária ou de formação humanista (entendido este termo, "humanismo", em sentido amplo e não apenas em sentido tradicional) ou de cultura geral deveria se propor a tarefa de inserir os jovens na atividade social, depois de tê-los levado a um certo grau de maturidade e capacidade, à criação intelectual e prática e a uma certa autonomia na orientação e iniciativa. (GRAMSCI 1988, P. 121)

Levando em consideração que o modelo de sociedade em que vivemos é nefasto, faz-se necessário um maior estudo acerca da proposta de Gramsci quando este aborda o tema da escola unitária, pois atende a um princípio básico, que é a defesa da emancipação humana.

A organização do trabalho cultural, alicerçado pela proposta da escola unitária, deverá ser desenvolvida cuidadosamente, em todas as suas partes e servir de guia na constituição mesmo do mais elementar e primitivo centro de cultura.

Neste sentido, não podemos nos furtar ao fato de que a ação dos intelectuais interfere diretamente na formação dos sujeitos, portanto da formação da cultura, pois a escola absorve como a própria sociedade, os pensamentos dos mesmos, portanto, retransmitindo-os reduzidos por estes intelectuais à ordem do capital. Assim sendo é fundamental que a ação destes intelectuais tenha um direcionamento revolucionário, de discutir a situação vigente, se posicionar criticamente, na direção da contra-hegemonia, ou da hegemonia do proletariado.

A escola tem, em última análise, a função social de instruir os sujeitos, e esta instrução deve ser, sempre, numa perspectiva de superação das condições de opressão, e avanço para a diminuição ou até a extinção de teorias deturpadas sobre a educação. Hoje temos um modelo de educação baseado nas teorias construtivistas, que o pesquisador Newton Duarte denomina de "aprender a aprender". Esta teoria tem suas bases na ideologia capitalista.

Sobre esta perspectiva ideológica de educação, podemos identificar que esta tendência pedagógica dialoga com o sistema capitalista, pois treina as crianças para o trabalho, não para a construção de um indivíduo crítico e voltado para a mudança social.

Em seu livro Sociedade do conhecimento ou sociedade das ilusões Duarte (2003), faz uma crítica a esta teoria, alicerçado nas bases epistemológicas postuladas por seus teóricos, e, fazendo a análise de uma das passagens do texto ele afirma: 
O autor não deixa qualquer dúvida quanto ao fato do "aprender a aprender" ser apresentado como uma arma na competição por postos de trabalho, na luta contra o desemprego. O "aprender a aprender" aparece assim na sua forma mais crua, mostrando seu verdadeiro núcleo fundamental: tratar-se de um lema que sintetiza uma concepção educacional voltada para a formação, nos indivíduos, da disposição para uma constante e infatigável adaptação à sociedade regida pelo capital. (DUARTE, 2003. p.11)

Esta passagem nos indica qual o caráter da teoria em questão, qual seja, o caráter adaptativo, que vincula o conhecimento ao mundo do trabalho, sem que se faça a crítica sobre a realidade social, e sem propor mudanças, caso fosse identificada a necessidade desta. Para reforçar esta idéia, Duarte continua afirmando que:

O caráter adaptativo dessa pedagogia está bem evidente. [...] Aos educadores caberia conhecer a realidade social não para fazer a crítica a essa realidade e construir uma educação comprometida com as lutas por uma transformação social radical, mas sim para saber melhor quais competências a realidade social esta exigindo dos indivíduos. Quando educadores e psicólogos apresentam o "aprender a aprender" como síntese de uma educação destinada a formar indivíduos criativos, é importante atentar para um detalhe fundamental: essa criatividade não deve ser confundida com busca de transformações radicais na realidade social, mas sim [...] adaptação aos ditames da sociedade capitalista. (DUARTE, 2003. p.12)

As passagens acima reforçam a ideia da escola como aparelho destinado a obedecer aos propósitos de uma cúpula dominante, que neste caso é quem deveria cuidar do nosso bem estar e crescimento em todos os seus aspectos, o Estado, comandado pelo capitalismo. Mas isso não deveria causar tanta impressão, pois a LDB, 9392/96, no seu artigo primeiro, inciso segundo, traz de forma muito clara qual o propósito da escola, ou como citado no texto, educação escolar. Então citado no texto está: "A educação escolar deverá vincular-se ao mundo do trabalho e à prática social" (SAVIANI, 2006. p. 163).

Aferida a análise feita por Saviani, e adentrando a proposta de Gramsci, quando ele aborda a questão da educação, este concebe uma proposta de formação humana que é oposta à proferida nas escolas, que é a escola "desinteressada".

Quando este autor fala em escola "desinteressada", está querendo nos colocar não só um termo particular, mas uma proposta coesa e complexa de educação, baseada na real necessidade da sociedade, e não no que somos direcionados a acreditar enquanto necessário para a nossa vida.

O termo "desinteressada", a princípio, sugere e nos indica o contrário do que exatamente ele quer nos dizer. Neste sentido, "desinteressada" pode ser traduzido como algo que transcende os interesses capitalistas de educação. Ou seja, entende que a escola deve ter a função principal de formar o sujeito numa perspectiva socialista, interessada na construção de um sujeito emancipado e crítico; voltado para a construção de um sujeito que tenha na sua base intelectual e objetiva da vida social as "armas" para a construção do ser completo. Em suma, esta concepção de educação tem como princípio a formação do sujeito coletivo, solidário, mais humano, o que foge totalmente à concepção capitalista de escola (NOSELLA, 2004).

Defendemos que os intelectuais não podem se esconder atrás da neutralidade cientifica e ficarem alheios às contradições contemporâneas, tendo a necessidade de 
abandonarem o silêncio diante dos fatos, se definirem nos conflitos da história e tomarem partido, pois urge construirmos um projeto alternativo, originado pelo proletariado, para conquista da sua hegemonia, com o apoio dos intelectuais "orgânicos" às classes populares, à luta pela democratização do poder, pela expansão dos direitos, pela eliminação da violência em todas as suas esferas: simbólica, física, psíquica e verbal. Agindo assim, poderão contribuir para desvendar contradições sociais e colocar em xeque a concepção de dominação, de autoritarismo e de burocratismo existentes em nossa sociedade e quem as mantém. Todavia, as estratégias burguesas de cooptação dos intelectuais impõem barreiras tanto subjetivas quanto e, principalmente, objetivas na atuação dos que se propõem a uma luta de resistência a todo o processo de dominação.

Nesse cenário, parece estarmos assistindo à decadência dos intelectuais militantes, críticos e pesquisadores e em seus lugares emergindo intérpretes, gerentes, divulgadores, especialistas de reformas. Tem se tornado difícil nos referirmos a "intelectual orgânico", às classes trabalhadoras diante de tantas ressignificações em nossa sociedade, cujas organizações de classe: os próprios partidos e os sindicatos, muitas vezes, vêm desconsiderando essa luta. Destaca-se, entretanto, que o legado do "intelectual orgânico" ainda prevalece como horizonte a ser atingido em nossa realidade. Faz-se necessário que nos formemos, bem como formemos intelectuais que não caiam na mecanização e na escravidão do sistema, se atualizando e desenvolvendo pesquisas junto às comunidades, sem se deixarem taylorizar e serem cooptados, mas, acima de tudo, lutarem pelo reconhecimento do saber popular, a construção democrática e coletiva de um projeto público de sociedade em que defendam a elevação moral e intelectual das massas.

Em outras palavras, a capacidade de defender um projeto de sociedade que reconheça e contemple os dominados como sujeitos políticos, que ao ocupar posições de resistência não traiam a cumplicidade com os movimentos populares, continuem exercendo o papel crítico e revolucionário e não de "funcionários" de partido e de gerentes técnico-administrativos dos aparelhos de poder governamental, verdadeiros especialistas em estratégias eleitorais, em profissionais da imagem, em artimanhas jurídicas, em hibridismo ideológico e tráfico de influência.

A escola pode e deve ser uma instituição construtora de conhecimentos emancipatórios, que contribuam para possibilitar o indivíduo agir conscientemente; engajando-se na luta por transformações das condições perversas, injustas e negadoras da dignidade humana. Para isso, é necessário construir outra hegemonia diametralmente oposta a que está posta.

As mudanças ocorridas no âmbito socioeconômico (supremacia do mercado), político e cultural (poderio da comunicação), trouxeram alterações significativas na própria natureza das atividades intelectuais. Contudo, os horizontes culturais e históricos defendidos por Gramsci ainda necessitam ser vislumbrados, destacando que a função dos novos intelectuais se constitua hoje como algo fundamental.

A atuação dos intelectuais entre a classe trabalhadora é de fundamental importância, mesmo que estes não pertençam a esta classe, mas desde que se coloquem no lugar desta e lutem pela sua transformação. Logo, é cada vez mais necessário insistir na formação de intelectuais da classe trabalhadora para que ela alcance emancipação através de uma consciência humanística em detrimento da consciência posta, qual seja, a de mercado, desenvolvendo, assim, sua cultura e sua educação.

Os intelectuais possuem uma função orgânica bastante importante no processo da reprodução social, na medida em que ocupam espaços sociais de decisão prática e 
teórica. Mas, para Gramsci, a principal função destes se encontra na formação de uma nova moral e uma nova cultura, que podem ser entendidas também como uma contrahegemonia, já que o objetivo final das lutas organizativas seria, no seu momento histórico, o socialismo.

E claro que não seria possível falar de intelectuais e hegemonia sem falar em educação e escola, objeto de intensa preocupação de Gramsci, já que ele considera a escola e a educação como sendo um aparelho privado de hegemonia. Assim, apontamos, neste trabalho algumas ideias adensando a perspectiva da formação humana para a emancipação, considerando a escola como um espaço de desenvolvimento ideológico contra-hegemônico.

As contribuições de Gramsci continuam atuais e necessárias, pois o capitalismo em suas diversas formas apenas se recicla, reforma. Nesse processo, os intelectuais que atuam em defesa de uma lógica burguesa acabam reforçando esse modelo reformista que encobre os problemas concretos e atuam na superficialidade dos fatos e nas subjetividades da grande massa populacional, levando-as a crer que a reforma é, de fato, a saída frente às problemáticas enfrentadas. $\mathrm{O}$ capital se constitui de ciclos reformistas que acabam "viciando" estratégias que não resolvem concretamente seus problemas, pois não atingem a essência que os provoca e os faz ressurgir com uma nova "roupagem".

Ao contrário desta lógica, a proposta apresentada por Gramsci indica uma ruptura com esse modelo, instigando a transformação em sua totalidade e complexidade, por meio de uma crítica rigorosa, possibilitando a alteração da lógica social e apontando a perspectiva da proposta socialista como possível e mesmo necessária.

Para Gramsci (1982), o processo hegemônico vincula o ato pedagógico ao político. Ambos isolados não concretizam, de forma plena, o estado hegemônico. A educação das massas, para a elevação de sua cultura, é um ato preliminar que serve de suporte à tomada de poder.

A formação política é um constante desafio para quem se propõe ser educador, seja esse desafio formal ou não-formal. $\mathrm{O}$ ato político é colocado como elemento de formação que caracteriza o sujeito como agente da sua história. Para Gramsci (1999), existem fundamentos que não podem ser colocados de lado, que não podem deixar de acompanhar o processo. Estes fundamentos se caracterizam pela luta ininterrupta da propaganda ideológica. Gramsci acredita que o novo intelectual deve ter um modo de ser diferenciado do anterior, que utilizava da sua eloquiência como motor de sua ação. O novo intelectual deve inserir - se ativamente no cotidiano da vida política, como organizador permanente, como construtor e não apenas como "orador puro - mas superior ao espírito matemático abstrato; da técnica-trabalho, chega à técnica-ciência e à concepção humanista histórica, sem a qual permanece 'especialista' e não se torna 'dirigente' (especialista + político)." (GRAMSCI, 2000, p. 53).

\section{Considerações finais}

O presente texto objetivou refletir acerca da função dos intelectuais para manter ou para modificar a lógica do capital e a sua funcionalidade; conservar ou alterar o modo de produção da vida e as perspectivas de ação política e social, bem como sinalizar para a necessidade de formarmos intelectuais que oportunizem a alteração das condições de vida, de ação e de organização da sociedade como um todo e dos trabalhadores, em particular. 
Nesta ação, articulação, a atividade política e intelectual, teórica e prática, pedagógica e militante dos intelectuais deve ser revista e considerada numa perspectiva de alteração da lógica imposta pelo capitalismo. Urge que este "intelectual" auxilie na articulação da lógica revolucionária, em contraposição à intelectualidade cooptada pela lógica do capital, que funciona para a classe dominante no sentido de manutenção da ordem, especializando-se, cada vez mais, nas funções de administração, gestão e controle social.

Pretendemos chamar a atenção para a urgência de uma reflexão nova e rigorosa sobre o papel dos intelectuais, e a importância dos lugares que ocupam na esfera educacional, em especial nas escolas e universidades. Marx já afirmara que as ideias só adquirem força material quando penetram nas massas.

De acordo com Semeraro (2006), o "novo" intelectual (que não é apenas um indivíduo, mas é também constituído por diversos sujeitos políticos organizados), enquanto analisa criticamente e trabalha para "desorganizar" os projetos dominantes, se dedica a promover uma "nova inteligência social", capaz de pensar a produção, a ciência, a cultura, a sociedade na ótica da classe subjugada à qual pertence.

Partindo deste pressuposto, frisa que, no Brasil, a recente crise política e cultural vem gerando um amplo debate para rediscutir a função dos intelectuais na sociedade, e à figura do "intelectual orgânico" delineada por Gramsci, no sentido socialista. Em outras palavras, é o sujeito imbricado na filosofia da práxis, e, com ela, novos intelectuais politicamente compromissados com o próprio grupo social para juntos fazer e escrever a história e, sendo, capazes de refletir sobre a articulação da produção material à sua distribuição, conhecer o funcionamento da sociedade, descobrir os mecanismos de dominação encobertos pela ideologia dominante e os enfrentamentos das classes na disputa pelo poder.

A escola, portanto, está diante do desafio de criar condições para formar sujeitos críticos, em condições de superação dos processos ideológicos que oprimem e impedem a emancipação dos mesmos. O que nos leva a defender uma redefinição do que seja um intelectual. Por isso é que devemos ficar atentos, principalmente, ao papel dos professores e educadores, em suas posturas, em seus discursos, em suas práticas, pois a escola é a porta de entrada, é a porta de entrada por onde se internaliza e se espalha, com mais facilidade, a ideologia capitalista. O professor, o educador devem assumir uma postura política, e, assim, poder atuar revolucionariamente na formação dos educandos direcionando o pensamento para a alta esfera do pensamento intelectual e político.

Os pressupostos defendidos por Gramsci alertam-nos para a função dos intelectuais e, em especial, para as necessárias ações de produção do conhecimento, organizativa e educativa. De outra forma chama-nos a atenção para a necessidade da formação de intelectuais "orgânicos", contrários a lógica do capital, hegemônica na sociedade atual. Nesse sentido, a sociedade capitalista ao tempo em que cria um conjunto variado de intelectuais orgânicos para perpetuar a sua hegemonia, arrisca-se a inibir a formação de intelectuais orgânicos para as classes subalternas, e com isso busca manter o reformismo e postergar a "revolução cultural" da classe trabalhadora em nossa sociedade.

A importância dos intelectuais "orgânicos" de posicionamento socialista na sociedade é de fundamental interesse da própria sociedade que vislumbra a saída desse sistema. É isso que propõe Gramsci. A transformação da sociedade é possível, mas para isso é deveras importante que o pensamento seja revolucionário, que o pensamento seja o de superação da lógica do capital. 


\section{Referências}

ANGELI, José Mario. Gramsci, hegemonia e cultura: relações entre sociedade civil e política. Vol 11, No 122 (2011): Revista Espaço Acadêmico, nº 122, julho de 2011.

BOTTOMORE, Tom. Dicionário do pensamento marxista. 5. reimp. Jorge Zahar ed., 1997.

DUARTE, Newton. Sociedade do conhecimento ou sociedade das ilusões? Quatro ensaios críticos-dialéticos em filosofia da educação. Campinas: Autores Associados, 2003.

FERRONI, Giulio. Gramsci e os modelos intelectuais no século XX. Disponível em: <http://www.lainsignia.org/2007/marzo/cul_018.htm> Acesso em: 10 de julho de 2011.

GRAMSCI, Antonio. Os intelectuais e a organização da cultura. Tradução de Carlos Nelson Coutinho. $4^{a}$ Ed. Rio de Janeiro: Civilização Brasileira, 1982.

Os intelectuais e a organização da cultura. Tradução de Carlos Nelson Coutinho. $6^{a}$ Ed. Rio de Janeiro: Civilização Brasileira, 1988. 1995.

Os intelectuais e a organização da cultura. Rio de Janeiro: Civilização Brasileira,

. Cadernos do cárcere, volume 1. Rio de Janeiro: Civilização Brasileira, 1999.

Cadernos do cárcere, volume 2. Rio de Janeiro: Civilização Brasileira, 2000.

LOMBARDI, José Claudinei; SAVIANI, Dermeval (Orgs.). Marxismo e educação: debates contemporâneos. Campinas, SP: Autores Associados: HISTEDBR, 2005.

MAESTRI, Mário; CANDREVA, Luigi. Antonio Gramsci: vida e obra de um comunista revolucionário. 2 ed. São Paulo: Expressão popular, 2007.

MARI, Cezar Luiz de. O papel educador dos intelectuais na formação ideológica e hegemônica em Gramsci: uma perspectiva de emancipação humana. - UFSC. Disponível em: <www.anped.org.br/reunioes/26/trabalhos/cezarluizdemari.rtf> Acesso em: 13 de julho de 2011

MARTINS, Marcos Francisco. Conhecimento e disputa pela hegemonia: Reflexões em torno do valor ético - político e pedagógico do senso comum e da filosofia em Gramsci. pp. 123 - 159.In: LOMBARDI, José Claudinei; SAVIANI, Demerval (orgs). Marxismo e Educação: debates contemporâneos. Campinas, SP: Autores Associados; HISTEDBR, 2005

MARX, Karl. Glosas críticas marginais ao artgo ö rei da Prússia e a reforma social" de um prussiano. 1 ed. São Paulo: expressão popular, 2010.

Contribuição à crítica da filosofia do direito de Hegel: introdução. 1 ed. São Paulo: expressão popular, 2010.

MÉSZÁROS, Iztván. A educação para além do capital. São Paulo: Boitempo, 2005

NOSELLA, Paolo. A escola de Gramsci. 3 ed. Rev. E atual. São Paulo: Cortez, 2004.

PINTO, Laudicéa de Souza. Gramsci e os Intelectuais. Disponível em: <www.achegas.net/numero/onze/laudicea_pinto_11.htm> Acesso em> 13 de julho de 2011

SANTOS, Jordana Souza. Gramsci e o papel dos intelectuais nos movimentos sociais. Disponível em:

<http://periodicos.uem.br/ojs/index/php/EspacoAcademico/article/viewFile/7128/481>

Acesso em: 11 de julho de 2011 
SAVIANI, Dermeval. A nova lei da educação: LDB trajetória, limites e perspectivas.10 ed. Campinas: Autores associados, 2006.

SAVIANI, Dermeval. Escola e democracia: teorias da educação, curvatura da vara, onze teses sobre a educação e política. São Paulo: Cortez: Autores Associados, 1984.

SEMERARO, Giovani. Intelectuais "organicos" em tempos de pós-modernidade. Cad. CEDES, v. 26, n. 70. Campinas set./dez. 2006. Disponível em: <http:www.achegas.net/numero/onze/laudicea_pinto_1.htm>

Letras, 2006

Gramsci e os novos embates da filosofia da práxis. Aparecida, SP: Idéias \&

SILVA, Luiz Etevaldo. Sociedade, Política e Cultura em Gramsci. Theoria - Revista Eletrônica de Filosofia. Disponível em: <http://www.theoria.com.br/ edicao0310/sociedade_politica_e_cultura_em_gramsci.pdf $>$ Acesso em: 12 de julho de 2011.

Vocabulário Gramsciano. Filosofia e Questões Teóricas. Disponível em: < http://www.socialismo.org.br/portal/filosofia/152-documento/246-vocabulariogramsciano>. Acesso em: 08 de julho de 2012

Notas:

1 Doutoranda PPGE/ FACED/ UFBA, Grupo de Pesquisa HCEL, Bolsista CAPES. Email: cida.ufu@gmail.com

${ }^{2}$ Mestre PPGE/ FACED/ UFBA, Grupo de Pesquisa HCEL

${ }^{3}$ Professora PPGE/ FACED/ UFBA, Grupo de Pesquisa HCEL, CAPES (Pós-doutorado Programa de Cooperação CAPES-COFECUB).

${ }^{4}$ Graduado Pedagogia UNEB. Grupo de Pesquisa HCEL

${ }^{5}$ Ao longo do texto, a categoria intelectuais "orgânicos" será explicitada tanto em Gramsci quanto para pesquisadores em Gramsci. Partimos do pressuposto e da compreensão de que "orgânicos" são aqueles intelectuais que são a expressão direta de uma determinada classe e dos seus interesses; proveniente da classe social que o gerou, tornando-se seu especialista, organizador e homogeneizador. Todavia, tal explicação deixa brechas para a consideração que o intelectual orgânico pode atender aos interesses do capital também, pois irá atuar na mesma lógica. Ou seja, será comprometido com a causa, pensará formas de dominação, articulará essas formas de dominação com a escola, dentre outras práticas. Por isso que o que determina para onde vai esta produção intelectual orgânica é a tendência ideológica de cada sujeito produtor daquele conjunto de ações sociais às quais ele está apresentando, ou representando.

${ }^{6}$ Para Gramsci (1995), a hegemonia seria a direção moral e intelectual de uma sociedade, onde a dominação "física" e corpórea é auxiliada pela instauração do consenso. O poder de coesão, conectado ao consenso, constituiria o predomínio de uma visão social de mundo e de convívio social.

No vocabulário gramsciano, Aldo Tortorella afirma que o conceito gramsciano de hegemonia se contrapõe, nos Cadernos do cárcere, à ideia de "dominação". Somente numa fase tosca e primitiva é que se pode pensar numa nova formação econômica e social como dominação de uma parte da sociedade sobre outra. Na realidade, o que uma hegemonia estabelece é um complexo sistema de relações e de mediações, ou seja, uma completa capacidade de direção. Gramsci fornece uma série de exemplos históricos, em particular o da hegemonia dos moderados na França do século XIX ou na Itália. Não haveria organização do poder moderado somente com o uso da força. É um conjunto de atividades culturais e ideológicas - de que são protagonistas os intelectuais - que organiza o consenso e permite o desenvolvimento da direção moderada. 
Para Martins (2005) diante do novo contexto do século XX, no qual a disputa pela hegemonia se faz também no âmbito cultural e ideológico e nas sociedades de tipo ocidental a burguesia só é dominante economicamente e dirigente no ponto de vista ético e político porque, além de conquistar o território das relações de produção material, concomitantemente disseminou e consolidou no meio social uma visão de mundo que a legitima como hegemônica. Nesse sentido, ciente da politização da epistemologia, isto é, sabendo que há toda uma sistemática de criação e difusão de conhecimento colocada em funcionamento para favorecer a hegemonia burguesa em vigor, Gramsci procurou forjar uma inovadora estratégia contrahegemônica. E fez isso partindo da situação concreta, da e na dinâmica que estava em pleno funcionamento na realidade do capitalismo vivido por ele no início do século XX.

${ }^{7}$ Neste caso contra-hegemonia pode ser compreendida como a ação de uma determinada sociedade que tem como objetivo a derrubada de um determinado grupo social que tem o controle, ou seja, que possui hegemonia perante uma sociedade. Este novo modelo de sociedade que é colocado nestes termos tem que ser obrigatoriamente oposto ao modelo anterior, ao modelo hegemônico que se pretende derrubar. No caso do capitalismo, o socialismo.

${ }^{8}$ Por questões de espaço para escrita, não será possível desenvolver detalhadamente obre a influência do comportamento dos intelectuais setentrionais perante os meridionais. Em futuras pesquisas pretende-se aprofundar mais estas influências históricas, que segundo Nozella (2004) migraram do partido comunista italiano para o movimento fascista, como Croce, Marinetti, De Gaspari, Pirandenllo dentre outros. Ou seja, tal ação fez com estes se colocassem na contramão da revolução que Gramsci propunha desde quando da época do Ordem Nova.

9 Estas ideias adivinham dos dois grandes blocos que coexistiam no Sul: "o bloco agrário" e o "bloco intelectual". O primeiro era composto pelos grandes latifundiários que por sua vez atendiam a uma demanda nortista burguesa capitalista. O segundo constituía-se pelos grandes intelectuais sulistas "tradicionais" que atendiam as necessidades dos grandes latifundiários. Conforme Maestri; Candreva (2007, p. 182-183) estas ideias de dominação eram geradas pelos grandes intelectuais, representantes dos latifundiários, que conformavam um poderoso bloco intelectual. Neste bloco, destaca Giustino Fortunato e Benedetto Croce. A direção do bloco agrário permitia que os grandes latifundiários negociassem em troca do apoio aos interesses capitalistas hegemônicos, a conservação do status quo, congelando arcaísmo e econômico sulino, e sua dependência colonial ao norte.

Recebido em fevereiro/2012

Aprovado em agosto/2012 